\title{
Using Risk Terrain Modeling to predict homeless related crime in Los Angeles, California
}

Youngmin Yoo $^{1} \&$ Andrew P. Wheeler ${ }^{1, * *}$,

**Corresponding author, email: apwheele@gmail.com

1. School of Economic, Political, and Policy Sciences - Program in Criminology \& Criminal Justice

The University of Texas at Dallas

800 West Campbell Road, Mail Station GR 31

Richardson, Texas 75080-3021

Acknowledgements: We thank Joel Caplan and the Risk Terrain Modeling gratis program for the ability to conduct this research. 
Title: Using Risk Terrain Modeling to Predict Homeless Related Crime in Los Angeles, California

Abstract: We apply Risk Terrain Modeling (RTM) to identify the factors that predict homeless related crime at micro grid cells in Los Angeles, CA. We find that place based factors predicting whether homeless individuals are victimized or the offender being homeless are largely consistent with one another. Out of 26 different crime attractors and generators, prior drug arrests, homeless shelters, and bus stops are the three biggest factors in predicting homeless related crime. We show how the RTM model can effectively forecast future homeless related crimes as well. This suggests that targeted spatial strategies can reduce both homeless offending and victimization risk. Given that the majority of homeless individuals are only intermittently homeless, place based strategies may be a more an effective way to limit risk than strategies that focus on individuals.

Keywords: RTM, homeless, micro-place, victimization, offending

Original data and RTM output can be obtained at https://www.dropbox.com/s/a9kj0dk18mcy90e/LA_Homeless_RTM.zip?dl=0.

\section{Introduction}

This article presents an application of Risk Terrain Modeling (RTM) (Caplan, Kennedy, \& Miller, 2011) applied to predicting spatial areas of high risk of homeless related crime in Los Angeles, California. Homeless populations present significant challenges for law enforcement. The total number of homeless individuals has been rising in the United States in recent years, with an estimated total of over half a million homeless in the US in 2017 (US News, 2017). Tackling problems related to homelessness is intrinsically related to policing (Bittner, 1967; Huey, 2007; White, 2010). Homeless individuals are at higher risk of both being victimized by crime (Diette \& Ribar, 2018; Ellsworth, 2018) as well as at higher risk of committing crime 
(Crawford, Whitbeck, \& Hoyt, 2011; Listwan, Hartman, \& LaCourse, 2018). Even absent involvement in serious crimes, loitering and camping in public places are frequently a citable offense (Berk \& MacDonald, 2010; Robinson, 2017; Stuart, 2016), and as such police are often tasked with dealing with homeless individuals and the subsequent disorder they are associated with (Vitale, 2010).

Homelessness is intrinsically related to the built environment - different outdoor structures provide temporary shelter for transient individuals (such as bridges), and these factors are fixed in space. These aspects of the built environment place unique constraints on the routine activities of homeless individuals, and as such they are particularly suited to predict the locations of homeless related crime. Given those spatial factors apply equally to all homeless individuals, we additionally predict those factors will work equally well to predict either homeless offending or homeless victimization. As such, this work will add to the voluminous literature that has identified various individual level risk factors for homeless individuals (Ellsworth, 2018), and provide spatial risk factors that can predict homeless crime risk. This is an advancement over the limited prior work on the spatial patterns of homeless related crime, as it has focused on general crime increases around homeless shelters or other homeless encampments, and did not examine offending or victimization specifically by homeless individuals (Berk \& MacDonald, 2010; Faraji, Ridgeway, \& Wu, 2018).

We believe applying RTM to homeless related crime can also help inform future criminal justice strategies in Los Angeles in several ways. One is that by identifying the potential spatial factors that contribute to higher homeless crime risk, RTM can guide problem oriented policing or crime prevention through environmental design strategies to mitigate that risk. This is opposed to current order-maintenance approaches, such as the use of arrest and citations, that have 
negative externalities on the homeless and can be costly (Stuart, 2016; Wilking et al., 2018). Identifying types of places that are associated with high risk can identify potential solutions to homeless crime problems that do not strictly rely on traditional arrest based strategies (Chamard, 2010; Eck, 2018).

Second, prior police crackdowns on homeless related disorder focusing on Skid Row in Los Angeles only resulted in minor crime reductions, and likely caused subsequent displacement of homeless individuals (Vitale, 2010). We will show that while homeless related crime is concentrated in Los Angeles' Skid Row, it extends out in various places around Los Angeles. RTM by design can identify areas where crime displacement is likely to occur, and thus suggest proactive strategies to simultaneously address high risk places that goes beyond typical hots spots policing strategies.

\section{Literature Review}

\section{Homelessness and Crime}

The majority of prior work examining homeless related crime has been focused at the individual level, either through self-reported surveys or ethnographies; see Ellsworth (2018) for a review. Previous literature has identified that homeless individuals are both at high risk of victimization as well as offending. For example, Lee \& Schreck (2005) find that different risky lifestyle behaviors (such as sleeping outdoors or panhandling), increase ones risk of violent and property victimization, along with other more distal and demographic factors in a cross-sectional survey. Diette \& Ribar (2018) examine victimization in a longitudinal panel design, and find that housing insecurity increases future risk of violence, independent of prior risks of violence. The findings appear similar for offending as well, with Crawford, Whitbeck, \& Hoyt (2009) finding that self-reported measures of violent offending among a sample of juveniles were more likely 
among homeless youth that participated in selling drugs or were in a gang, as was a history of caretaker abuse. While the majority of this work focuses on self-reported measures of offending and victimization, the few studies that do examine official arrest measures also illustrate that homeless have a high risk of offending (Jeanis, Fox, \& Muniz, 2018; Listwan et al., 2018).

Two prior analyses have conducted spatial analysis related to homeless crime (Berk \& MacDonald, 2010; Faraji et al., 2018). Berk \& MacDonald (2010) analyzed the effect of the Safe Cities initiative by the Los Angeles Police Department, which was an order-maintenance policing strategy targeted at crime and disorder associated with homeless encampments in Skid Row. While they found some crime reductions, the program was criticized for its use of citations and arrests (Vitale, 2010).

Faraji et al. (2018) examine the impact that openings of emergency homeless shelters have on nearby crime counts. They find that when shelters are opened they increase the number of crimes nearby, and that when they close crime subsequently decreases. Neither of these articles specifically analyzed homeless related crime (in terms of being committed by or against a homeless individual); in each they simply measured trends and changes in overall crime counts. Thus in neither case can it be directly inferred the interventions specifically reduced offending by the homeless or victimization of the homeless (although reductions in at least one of those two categories is the most likely explanation of the results).

Despite the dearth of previous research, it may however, make sense to examine homeless related crime from a spatial lens. Homelessness is not a monolithic category. Most individuals are not chronically homeless, but experience more brief, intermediate spells (Diette \& Ribar, 2018). The needs of the intermittently homeless may be easier to address than the chronic homeless (Listwan et al., 2018), but the ability of the state to intervene on their behalf is 
much more limited. Being intermittently homeless by its nature makes it is much harder to identify when those particular individuals are currently homeless and offer services to mitigate any individual's risk.

Such intermittently homeless individuals are still at high risk of being victimized. Lee \& Schreck (2005) find that individuals who are more consistently homeless actually have lower victimization rates than those who are intermittently homeless, and attribute this to more experienced homeless individuals taken more precautions to prevent victimization. Thus it may be reasonable to take a proactive spatial approach in an attempt to reduce homeless crime risk, as opposed to using reactive tactics to address the needs of homeless individuals after they have been contacted by the police. Negative prior experiences with law enforcement tend to make homeless individuals distrustful and intentionally avoid law enforcement (Stuart, 2016), and so it may be necessary for police to proactively take steps to mitigate homeless victimization risk. As such, RTM is an appropriate tool to identify both the spatial areas of high risk, as well as identify environmental characteristics that increase risk of homeless related crimes.

\section{RTM and Place Based Criminology}

The theoretical motivation behind RTM is based on principles of environmental criminology. At its core is an assumption that crime events occur when an offender and victim meet in space, consistent with routine activities theory (Cohen \& Felson, 1979). But, routine activities theory fails to offer any explicit spatial predictions, as it was originally used to explain macro level changes in victimization rates. Crime pattern theory provides more explicit spatial predictions (Brantingham \& Brantingham, 1993): while crimes are still determined where victims and offenders meet in space, the chance of those meetings are more likely to occur in specific spatial areas that are more frequently used by multiple individuals. Brantingham \& 
Brantingham (1993) expressed where those areas where multiple individuals are more likely to meet via the environmental backcloth.

The environmental backcloth is made up of activity nodes in which individuals spend the majority of their time; such as a place of residence and where they attend school or work. The backcloth also includes paths between those nodes in which individuals travel. Those two areas define an individual's awareness space, which both predicts where offenders are likely to be aware of particular targets, as well as be exposed to a higher probability of victimization.

There are two major conceptions as to how the environmental backcloth can influence the spatial distribution of crime. The first is that the backcloth is highly predictive of where individuals go during their routine activities. Thus, crime is more likely to occur at particular places simply due to the convergence of more people in a smaller space. If one measures crime as a rate, it may mean the rate is constant, but the overall number of crimes (the numerator) varies over space because the denominator varies as well. Places with a larger number of individuals (the denominator) are often referred to as crime generators (Brantingham \& Brantingham, 1995). While one can measure the denominator in various ways (Andresen, 2006; Boggs, 1965; Gerell, 2018; Hipp, Tita, \& Boggess, 2011; Malleson \& Andresen, 2015), it is generally difficult to defend any particular measure as correct. When considering people as the unit at risk, they are highly dynamic within the day (Hipp, 2016; Hipp \& Kim, 2019) and over seasons (Linning, 2015). However, despite the potentially varying denominator over time, the relative effect of such activity nodes on crime appears to be constant over the day or across seasons (Haberman \& Ratcliffe, 2015; Haberman, Sorg, \& Ratcliffe, 2018).

It is also the case that not only do these crime generators influence crime at their exact location, but also increase the frequency of crime in nearby places (Bowers, 2014). The 
mechanism through which this diffusion takes place according to environmental criminology is that for an individual to travel between activity nodes, they take regular paths. The paths of many individuals may intersect, creating public areas with a high number of interactions, even if all individuals are not travelling to the same destination. It is also the case that one's risk of victimization appears much higher when travelling (Lemieux \& Felson, 2012). So for example, ones risk of being robbed is likely higher walking from a bar to a parking lot, as opposed to when they are inside the bar. Wheeler (2018b) showed that such spatial diffusion effects were often larger than the local effects of bars, liquor stores, and convenience stores across many different crime types. Given that homeless individuals are exposed in outdoor areas at a much higher rate than non-homeless individuals, it seems reasonable to expect such diffusion to extend to homeless related offending and victimization as well.

The second way that particular nodes may influence crime is that certain locations may actually change behavior. Due to more vulnerable targets within a location, it may be that motivated offenders are attracted to particular areas to commit a crime. For example, robbers may be more likely to target individuals walking in open air drug markets, as they carry cash and are not as likely to report the robbery to police (Bernasco \& Block, 2010). These locations are referred to as crime attractors (Brantingham \& Brantingham, 1995). In practice it is often difficult to tell the difference between a crime generator and a crime attractor, and places can simultaneously be both.

Besides actually drawing a motivated offender into a particular space, it may also be the case that a particular location may alter behavior in that space. What is considered reasonable behavior in a crowded bar is not the same as in a children's playground. Such an idea is incorporated into several different crime theories. For example, within Newman's (1973) theory 
of defensible space, he provides different examples of how different types of shared corridors can influence collective ownership of maintaining the area. In broken windows theory, the physical appearance of a location can signal to individuals that no capable guardians are present, and thus deviant behavior is more permissible (Wilson \& Kelling, 1982). These are examples of different behavior settings (Taylor, 2015). While it is difficult to explicitly define the borders of behavior settings, they are likely influenced by being nearby different activity nodes (McCord et al., 2007).

While the majority of the work in environmental criminology focuses on specific types of crimes (Barnum et al., 2017; Connealy \& Piza, 2019; Lersch, 2017), given that homeless are at high risk of committing or being victimized across many different crime types, it is likely the case that particular spatial risk factors are predictive across different crime types. Being homeless results in much more exposure to potential victimization than those who have the potential shelter of a home. The routine activities of the homeless are also heavily constrained by the built environment. Such as panhandling being more likely to occur around businesses and other places where people congregate (Scott, 2003). The built environment also constrains where one can rest for long periods of time in semi-sheltered areas. Thus RTM is an appropriate tool to identify those risk factors and generate a predictive model of future risk.

Finally, identifying spatial risk factors related to homeless crime offending or homeless crime victimization can potentially change strategies intended to reduce risk related to homeless populations. While RTM cannot explicitly dictate particular strategies, it is the first stage of problem analysis (Piza, Kennedy, \& Caplan, 2018). For example, if the locations of homeless shelters are identified as both a location in which homeless victimization and homeless offending is increased nearby, a police department may work directly with homeless shelters to identify 
ways in which they can reduce risk (such as via crime prevention through environmental design). This is opposed to arrest and citation based strategies, which may disperse the homeless to new locations but are unlikely to solve any particular homeless crime problem long term (Vitale, 2010).

\section{Data and Methods}

Dependent Variable: Homeless Related Crimes

The Los Angeles Police Department (LAPD) has publicly available incident level crime data geocoded to the address level (via the Los Angeles Open Data website, https://data.lacity.org/). The LAPD crime data also provides information to determine whether the incident was associated with a homeless offender, or whether the victim was homeless. The incident data is recorded based on the victim and officers perception (Brantingham, 2016), so not all homeless offenders were identified via arrest. The data for this study constructs the RTM models based reported homeless crimes from 2013 through 2017, and uses 2018 data to test the accuracy of the models.

Table 1: Crime Outcomes Under Study

\begin{tabular}{ccc}
\hline Outcome & Description & $\begin{array}{c}\text { Incident } \\
\text { Total }\end{array}$ \\
\hline Model 1 & Violence crime against Homeless & 3,689 \\
Model 2 & Violent crime committed by Homeless & 4,019 \\
Model 3 & Property crime against Homeless & 1,283 \\
Model 4 & Property crime committed by Homeless & 3,473 \\
\hline
\end{tabular}

We further disaggregate the risk models based on violent crime outcomes and property crimes. Violent crimes include aggravated assault, forcible rape, murder, and robbery. Property crime includes arson, burglary, larceny, and motor vehicle theft. Table 1 displays the total 
number of crimes by the two categories in the test sample (2013 through 2017), homeless offending or victimization and violent or property crimes. While a crime incident may include both a homeless offender or a homeless victim, the overlap of such events does not occur frequently in this data. Fewer than $5 \%$ of the incidents analyzed in this sample involve both a homeless victim and offender.

For the hold out 2018 sample there are a total of 6,307 homeless related crime incidents. These are analyzed collectively, as the analysis will show that the identified risk factors tend to be very similar across each of the four models.

\section{Independent Variables: Crime Generators and Crime Attractors}

Environmental characteristics that predict crime risk are broken down into either crime generators or crime attractors. As discussed in the literature review, such labels are somewhat arbitrary, but here are determined by whether all individuals likely access that service or area (crime generator), or whether that service or area is more limited to those of lower socioeconomic status or specific to the homeless (crime attractor). Due to the divergence of individuals using these facilities, we believe it is likely to influence the behavior settings of such locations (Caplan et al., 2017), although we cannot rule out such places have higher risk simply due to more homeless individuals interacting in a smaller space. While the labels are somewhat arbitrary, they do not have an impact on the resulting RTM analysis. Whether an independent factor is labelled as a crime generator or a crime attractor it undergoes the same variable selection routine in the subsequent models. 
Such variables were either collected from open data sources, or from Lexis Nexis business listings. ${ }^{1}$ All of these datasets were collected during the fall of 2018. While businesses opening and closing creates potential error in these measures (a business opened in 2017 cannot influence crime in 2016), we believe these errors are unlikely to greatly influence the results. The places were businesses can locate are heavily influenced by restrictive zoning that was established in LA long before the study period (Fishel, 2015). As such, even if one business closes, it is likely replaced by a similar establishment. It is also the case that physical infrastructure measures, such as sidewalks and bridges, also do not vary much over time. Table 2 lists the different independent variables used to predict homeless crime risk. There are a total of 20 different crime generator factors, and 6 different crime attractor factors.

Crime generators include areas that are potentially predictive of homeless encampments or sleeping rough locations (alleys, bridges, sidewalks, parks, streets). They also include services that homeless individuals frequently use, such as different public transit stations (bus stops, DASH stops, Express stops, metro stations), and libraries. Such places have been shown in prior work to correlate with crime (Groff \& La Vigne, 2001; Wheeler, 2018b). Finally, crime generators includes shopping places that homeless may either buy goods or potentially panhandle, such as convenience stores, drinking places, fast-food restaurants, gas stations, grocery stores, liquor stores, tattoo parlors, and shopping centers. Such locations are generally predictive of crime at micro places (Block \& Block, 1995; Burgason et al., 2017; Haberman \& Ratcliffe, 2015; Perenzin Askey et al., 2018; Wheeler, 2018b).

\footnotetext{
${ }^{1}$ While we are unaware of any prior criminological study using Lexis Nexis business directory data specifically, other crime and place based research has used commercial databases to obtain address level business listings (Bernasco \& Block, 2010).
} 
Table 2: Crime Generator and Crime Attractor Risk Factors

\begin{tabular}{|c|c|c|c|c|}
\hline \multicolumn{2}{|c|}{ Potential Risk Factors } & \multirow{2}{*}{$\begin{array}{r}\text { Counts (n) } \\
11,869\end{array}$} & \multirow{2}{*}{$\frac{\text { Data Type }}{\text { Polyline }}$} & \multirow{2}{*}{$\begin{array}{c}\text { Spatial Operationalization } \\
\text { Proximity }\end{array}$} \\
\hline \multirow{20}{*}{ Crime Generator } & Alleys & & & \\
\hline & Bridges & 2,297 & Point & Both Proximity and Density \\
\hline & Bus Stops & 10,994 & Point & Both Proximity and Density \\
\hline & Community DASH Stops & 1,621 & Point & Both Proximity and Density \\
\hline & Commuter Express Stops & 375 & Point & Both Proximity and Density \\
\hline & Convenience Stores & 402 & Point & Both Proximity and Density \\
\hline & Department Stores & 504 & Point & Both Proximity and Density \\
\hline & Downtown DASH stops & 204 & Point & Both Proximity and Density \\
\hline & Drinking Places & 400 & Point & Both Proximity and Density \\
\hline & Fast-food Restaurants & 2,074 & Point & Both Proximity and Density \\
\hline & Gas Stations & 1,893 & Point & Both Proximity and Density \\
\hline & Grocery Stores & 1,527 & Point & Both Proximity and Density \\
\hline & Libraries & 81 & Point & Both Proximity and Density \\
\hline & Liquor Stores & 1,432 & Point & Both Proximity and Density \\
\hline & Metro Stations & 55 & Point & Both Proximity and Density \\
\hline & Shopping Centers & 87 & Point & Both Proximity and Density \\
\hline & Tattoo Parlor & 132 & Point & Both Proximity and Density \\
\hline & Sidewalks & 1,844 & Point & Proximity \\
\hline & Parks & 321 & Point & Both Proximity and Density \\
\hline & Streets & 26,624 & Polyline & Proximity \\
\hline \multirow{6}{*}{ Crime Attractor } & Check-cashing store & 817 & Point & Both Proximity and Density \\
\hline & Homeless Shelters & 97 & Point & Both Proximity and Density \\
\hline & Laundromats & 642 & Point & Both Proximity and Density \\
\hline & Past Drug Arrests & 11,210 & Point & Density \\
\hline & Past Prostitution Arrests & 3,272 & Point & Density \\
\hline & Pawn Shops & 2,137 & Point & Both Proximity and Density \\
\hline
\end{tabular}

Crime attractor locations include additional stores that homeless may utilize. Checkcashing stores, and laudromats are areas where risk of victimization may be increased due to carrying cash (Kubrin \& Hipp, 2016). The same applies to pawn shops, but also provides a potential location to dispense of stolen goods. Homeless shelters likely increase the risk of crime (Faraji et al., 2018) both to and from homeless individuals. Finally, past drug and past prostitution arrests are typical indicators of crime attractors, as individuals who partake in such 
illicit behavior tend to be more attractive targets, again due to carrying cash and being less likely to report the victimization (Bernasco \& Block, 2010). Homeless individuals are also more likely to partake in such activities (Lee \& Schreck, 2005).

Spatial Units of Analysis and RTM

RTM is a raster based approach to measure how different place based factors (the previously discussed crime generators and crime attractors) are related to crime. As such, the spatial unit of analysis are micro place grid cells over the study area. To determine the resolution of the grid cells, we measured the mean length of a block in Los Angeles. This is approximately 480 feet, and so we constructed the grid cells to be half this size, 240 by 240 feet, which results in a total of 235,351 spatial units of analysis over the area of Los Angeles.

RTM is a technique that predicts counts of crime aggregated to those grid cells using count based regression models. Its main innovation is in two areas: first, it creates a consistent way to operationalize the effect of different risk factors on crime (Caplan et al., 2011). It reduces the effects of different crime generators to either proximity effects (i.e. a particular risk factor is within 1,000 feet), or density effects (i.e. whether there is a large number of that type of risk factor nearby). Table 2 displays whether the crime generator or attractor was operationalized as proximity effects, density effects, or both. Risks factors that are not points are operationalized as proximity. All other point patterns are operationalized as both proximity and density, with the exception of past drug and prostitution arrests. These events are so numerous and spread over Los Angeles that only measures of density would be reasonably predictive of future crime risk.

Given that one does not know generally a priori how far away a particular risk factor effects crime, the independent variables are calculated at several different distance bandwidths. Here we test six bandwidth distances of 240, 480, 720, 960, 1200, and 1440 feet. 
Both proximity and density measures are converted to $0 / 1$ indicators. Proximity effects are calculated as 1 if the crime generator or attractor is within that particular distance bandwidth. The density $0 / 1$ variable is created by calculating a kernel density estimate of the risk factor over the grid cells, using the distance bandwidth for the kernel estimator, z-scoring the density surface, and then scoring a grid cell as a 1 if its z-score is two or more. Because of the consistent operationalization of the spatial variables, effects can be easily interpreted in terms of the increase in relative risks of predicted crime when that independent variable is present.

If one estimates a regression model including all of these factors it would result in a regression analysis of 282 variables. $^{2}$ The second innovation in RTM is to use a novel variable selection technique to result in a more interpretable risk assessment model (Kennedy, Caplan, \& Piza, 2010; Kennedy et al., 2016). First, a constrained regression approach is used to select variables that have a positive coefficient on the crime outcome, using regularization to account for the fact that many of the independent variables are correlated. Second, using a stepwise procedure only one variable among the set of risk factors is chosen that minimizes the BIC criteria. For example, there are twelve different variables that measure either the distance or density of check cashing stores at the six different distance bandwidths. The stepwise procedure only selects at maximum one of those twelve check-cashing variables that produces the best BIC score. Finally, it chooses either a Poisson or negative binomial regression as the best fitting model (again by the BIC metric). We use the RTMDx software provided by the original creators of risk terrain modeling to conduct the regression analysis.

\footnotetext{
2 This includes 47 spatial risk factors (calculated by five risk factors measured as either proximity or density, and 21 risk factors measured as both proximity and density). Since each measure was calculated at six different distance bins, this results is $47 * 6=282$ variables.
} 
Subsequently RTM produces an estimated risk map, but is an improvement over typical hot spot maps in that it not only predicts areas of future high risk (Drawve, 2016), but also identifies potential causal factors that contribute to crime risk. It also potentially identifies areas that even if they are not currently hot spots of crime, are potential areas of crime displacement due to similar criminogenic environmental characteristics.

\section{Results}

Figure 1 displays a kernel density map of all homeless related crime in Los Angeles. The Skid Row neighborhood is highlighted in red on the map, and this establishes that while Skid Row has the highest overall risk based on past crime incidents, a significant amount of homeless crime risk extends beyond its borders. It is also the case that there are several different homeless related crime hot spot areas around LA. While such a simple mapping technique can identify the hot spots or specific areas to concentrate attention on, the following RTM analysis will identify potential causal factors that can additionally aid in a problem oriented policing approach (Caplan \& Kennedy, 2016). 


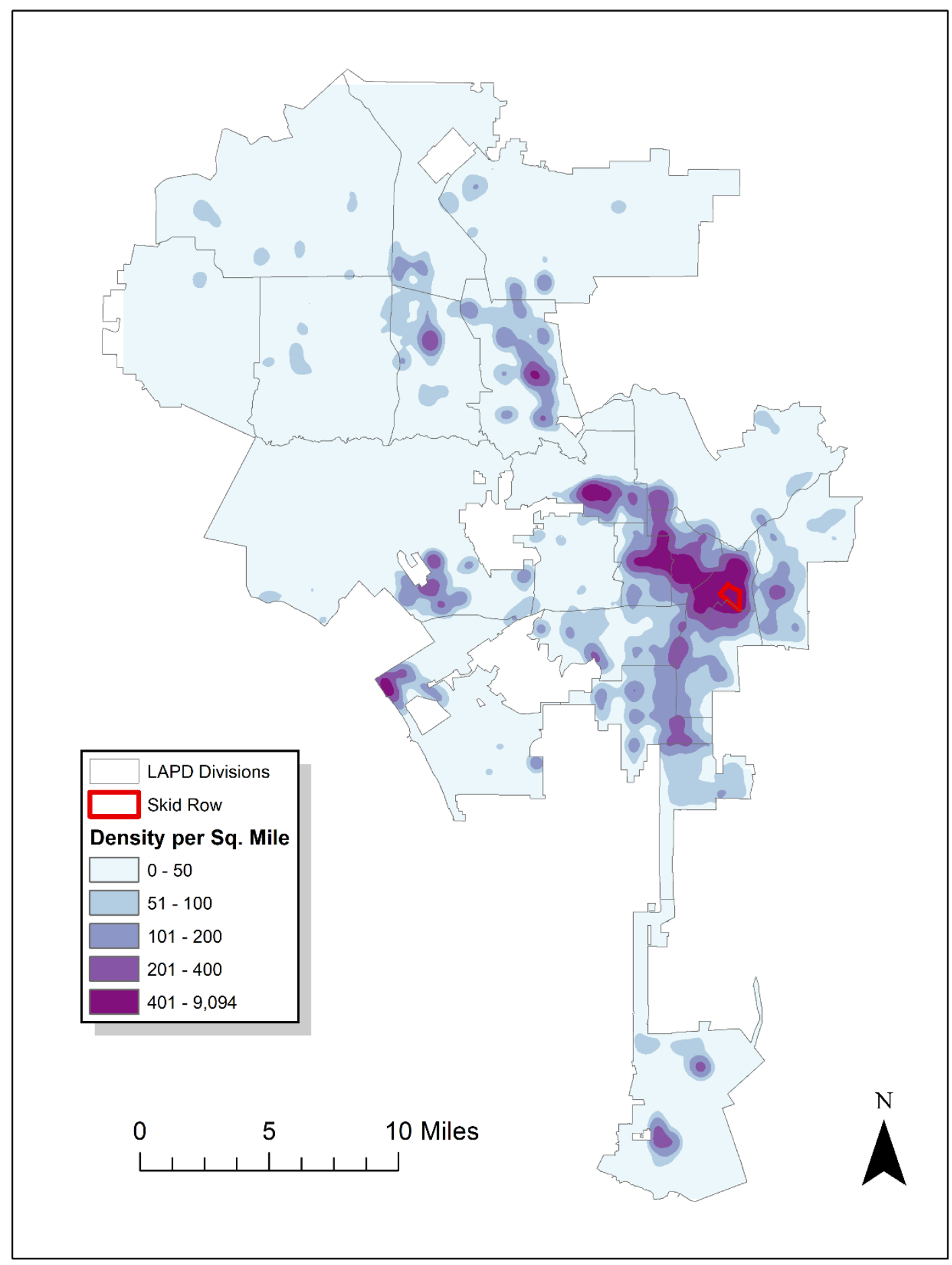

Figure 1: Kernel density estimate (KDE) of homeless related crime in Los Angeles, California, 2013-2017. Homeless related crime is defined as either the offender or the victim was recorded as being homeless. Included for reference are the location of City Council Districts, as well as the outline of the Skid Row neighborhood (in red). KDE is calculated using a 3,000 foot bandwidth. 
Table 3 lists the model selection results of the RTM analysis applied to the four different outcomes: violence against homeless, violence committed by the homeless, property crime against homeless, and property crime committed by the homeless. Each risk type lists the selected operationalization, either as a density (D) or proximity (P), along with the distance threshold that resulted in the best fitting model. The table also includes the relative risk value (RRV), comparing the added risk when that particular risk factor is present.

While several of the variables are not associated with any risk across all four models (alleys, sidewalks, streets, and tattoo parlors), the rest of the crime generator or crime attractor factors are significant contributors to homeless crime risk in at least one of the models. While alleys, sidewalks, and streets are locations where it is expected homeless are more likely to gather, they also are prevalent across most of the city, providing very little discrimination in predictions between high and low homeless crime areas. While the majority of relative risk factors are around the 1 to 2 range, several factors contribute to much higher estimated risk: homeless shelters and areas of the highest density of past drug arrests. These largest factors are consistent across each model, suggesting that these crime attractors contribute both to motivated offenders as well as suitable targets.

The distance of these largest risk factors are spatially limited: past drug arrests are either within 480 or 240 feet across each of the models. The effect of homeless shelters are selected at the 480 and 720 foot bandwidths. The spatial operationalization changes though for homeless shelters depending on the model, with crimes against homeless operationalized as proximity, but offenses committed by homeless operationalized as density. This suggests that placing multiple 
homeless shelters nearby one another increases homeless offending, but isolated homeless shelters may still have high homeless victimization risk.

Table 3: RTM Results

\begin{tabular}{|c|c|c|c|c|c|c|c|c|}
\hline \multirow[t]{2}{*}{ Risk Factor } & \multicolumn{2}{|c|}{$\begin{array}{c}\text { Model 1 } \\
\text { (Violence to } \\
\text { homeless) }\end{array}$} & \multicolumn{2}{|c|}{$\begin{array}{c}\text { Model } 2 \\
\text { (Violence by } \\
\text { homeless) }\end{array}$} & \multicolumn{2}{|c|}{$\begin{array}{c}\text { Model } 3 \\
\text { (Property crime } \\
\text { to homeless) }\end{array}$} & \multicolumn{2}{|c|}{$\begin{array}{c}\text { Model } 4 \\
\text { (Property crime } \\
\text { by homeless) }\end{array}$} \\
\hline & $\mathrm{SI} / \mathrm{O}$ & RRV & $\mathrm{SI} / \mathrm{O}$ & RRV & $\mathbf{S I} / \mathbf{O}$ & RRV & $\mathrm{SI} / \mathrm{O}$ & RRV \\
\hline \multicolumn{9}{|l|}{ Crime generator } \\
\hline Alleys & - & - & - & - & - & - & - & - \\
\hline Bridges & 1440 (D) & 1.4 & 1200 (D) & 1.4 & - & - & $480(\mathrm{P})$ & 1.8 \\
\hline Bus Stops & 720 (D) & 2.1 & 960 (D) & 1.9 & 960 (D) & 2.3 & $1440(\mathrm{P})$ & 1.8 \\
\hline Community DASH Stops & - & - & 240 (D) & 1.4 & - & - & $240(\mathrm{D})$ & 1.6 \\
\hline Commuter Express Stops & - & - & - & - & - & - & 1440 (D) & 1.8 \\
\hline Convenience Stores & - & - & 240 (D) & 1.6 & - & - & - & - \\
\hline Department Stores & 1200 (D) & 1.6 & 1200 (D) & 1.6 & $960(\mathrm{P})$ & 1.6 & $1200(\mathrm{P})$ & 1.9 \\
\hline Downtown DASH stops & $1440(\mathrm{P})$ & 2.2 & $1440(\mathrm{P})$ & 2.4 & $1440(\mathrm{P})$ & 3.7 & $1440(\mathrm{P})$ & 2.2 \\
\hline Drinking Places & - & - & - & - & - & - & 240 (D) & 2.9 \\
\hline Fast-food Restaurants & $1440(\mathrm{P})$ & 1.6 & 240 (D) & 1.7 & $1440(\mathrm{P})$ & 2 & $720(\mathrm{P})$ & 1.5 \\
\hline Gas Stations & 240 (D) & 1.5 & - & - & - & - & - & - \\
\hline Grocery Stores & 1440 (D) & 1.7 & $1200(\mathrm{P})$ & 1.9 & 1440 (D) & 1.6 & 480 (D) & 1.3 \\
\hline Libraries & - & - & - & - & 480 (D) & 2.2 & - & - \\
\hline Liquor Stores & $1440(\mathrm{P})$ & 1.9 & $1440(\mathrm{P})$ & 2 & $1440(\mathrm{P})$ & 1.8 & $240(\mathrm{D})$ & 1.7 \\
\hline Metro Stations & 480 (D) & 1.6 & $720(\mathrm{P})$ & 1.3 & 960 (D) & 1.7 & $720(\mathrm{P})$ & 2.3 \\
\hline Shopping Centers & - & - & 1200 (D) & 1.4 & - & - & $1440(\mathrm{P})$ & 2.2 \\
\hline Tattoo Parlor & - & - & - & - & - & - & - & - \\
\hline Sidewalks & - & - & - & - & - & - & - & - \\
\hline Parks & $1440(\mathrm{P})$ & 1.5 & $1440(\mathrm{P})$ & 1.5 & $1440(\mathrm{P})$ & 1.4 & - & - \\
\hline Streets & - & - & - & - & - & - & - & - \\
\hline \multicolumn{9}{|l|}{ Crime attractor } \\
\hline Check-cashing store & - & - & - & - & - & - & 1440 (D) & 1.2 \\
\hline Homeless Shelters & $480(\mathrm{P})$ & 4.9 & 720 (D) & 3.5 & $480(\mathrm{P})$ & 8.4 & 720 (D) & 2.9 \\
\hline Laundromats & - & - & - & - & - & - & $480(\mathrm{P})$ & 1.5 \\
\hline Past Drug Arrests & 240 (D) & 27.6 & 240 (D) & 23.1 & 240 (D) & 24.5 & 240 (D) & 22.7 \\
\hline Past Prostitution Arrests & $480(\mathrm{P})$ & 2.1 & 240 (D) & 2.2 & 240 (D) & 2.4 & $1440(\mathrm{P})$ & 1.5 \\
\hline Pawn Shops & - & - & $1440(\mathrm{P})$ & 1.4 & $960(\mathrm{P})$ & 1.3 & $960(\mathrm{P})$ & 1.4 \\
\hline
\end{tabular}

*SI (Spatial Influence), O (Operationalization), RRV (Relative Risk Value), P (Proximity), D (Density)

To simplify the results, we have placed the factors that had the highest risk associated with each of the models (according to the relative risk values) in Table 4. Besides the already 
mentioned past drug arrests and homeless shelters, Downtown DASH stops are within the top five relative risk factors across each crime type. Such a risk factor may not indicate increased risk when using a measure of the population using such services though (Gerrell, 2018).

Referring back to Table 3, the distance of the downtown DASH stops extends for a much larger area though - the model selected when they were within 1,440 feet as the best fitting results for each of the four models. Past prostitution arrests are within the top five risk factors for each model, with the exception of property crime by the homeless, although it is a much smaller risk factor than previous drug arrests.

Table 4: Top Five Risk Factors for Each Model

\begin{tabular}{ccccc}
\hline Priority & Model 1 & Model 2 & Model 3 & Model 4 \\
& $\begin{array}{c}\text { (Violence to } \\
\text { homeless) }\end{array}$ & $\begin{array}{c}\text { (Violence by } \\
\text { homeless) }\end{array}$ & $\begin{array}{c}\text { (Property crime to } \\
\text { homeless) }\end{array}$ & $\begin{array}{c}\text { (Property crime by } \\
\text { homeless) }\end{array}$ \\
\hline $\mathbf{1}$ & Past Drug Arrests (A) & Past Drug Arrests (A) & Past Drug Arrests (A) & Past Drug Arrests (A) \\
$\mathbf{2}$ & Homeless Shelters (A) & Homeless Shelters (A) & Homeless Shelters (A) & Homeless Shelters (A) \\
$\mathbf{4}$ & Downtown DASH stops (G) & Downtown DASH stops (G) & Downtown DASH stops (G) & Drinking Places (G) \\
$\mathbf{5}$ & Bus Stops (G) & Past Prostitution Arrests (A) & Past Prostitution Arrests (A) & Metro Stations (G) \\
& & Liquor Stores (G) & Bus Stops (G) & Downtown DASH stops (G)
\end{tabular}

NOTES: A: Crime Attractor; G: Crime Generator.

Figure 2 displays the RTM predicted risk map, combining all four models. Upon visual inspection of each individual risk map, they showed a large amount of spatial overlap, as would be expected based on the consistency of the different risk factors. ${ }^{3}$ The models were combined by taking the logs of the predicted relative risk, z-scoring that logged value, adding the four z-

\footnotetext{
${ }^{3}$ Another way to describe this overlap is to create binary high risk areas for each independent model (based on the typically used threshold in RTM analysis of a z-score of over two in the predicted area). Doing this exercise for each model, nearly $50 \%$ of the identified high risk areas were common to all four models.
} 
scores together, and then dividing by four. Compared to the original kernel density map, this provides a more detailed risk prediction surface based on the input crime generators. Although it still identifies the area of highest risk in and around Skid Row, it illustrates how there is risk of homeless related crime in multiple places around the city. While the overview map illustrates how risk often concentrates around different street corridors, if one zooms into more specific locations one can identify much higher risk scores around particular crime generators or attractors, which help to further filter risk locations to prioritize different interventions. 


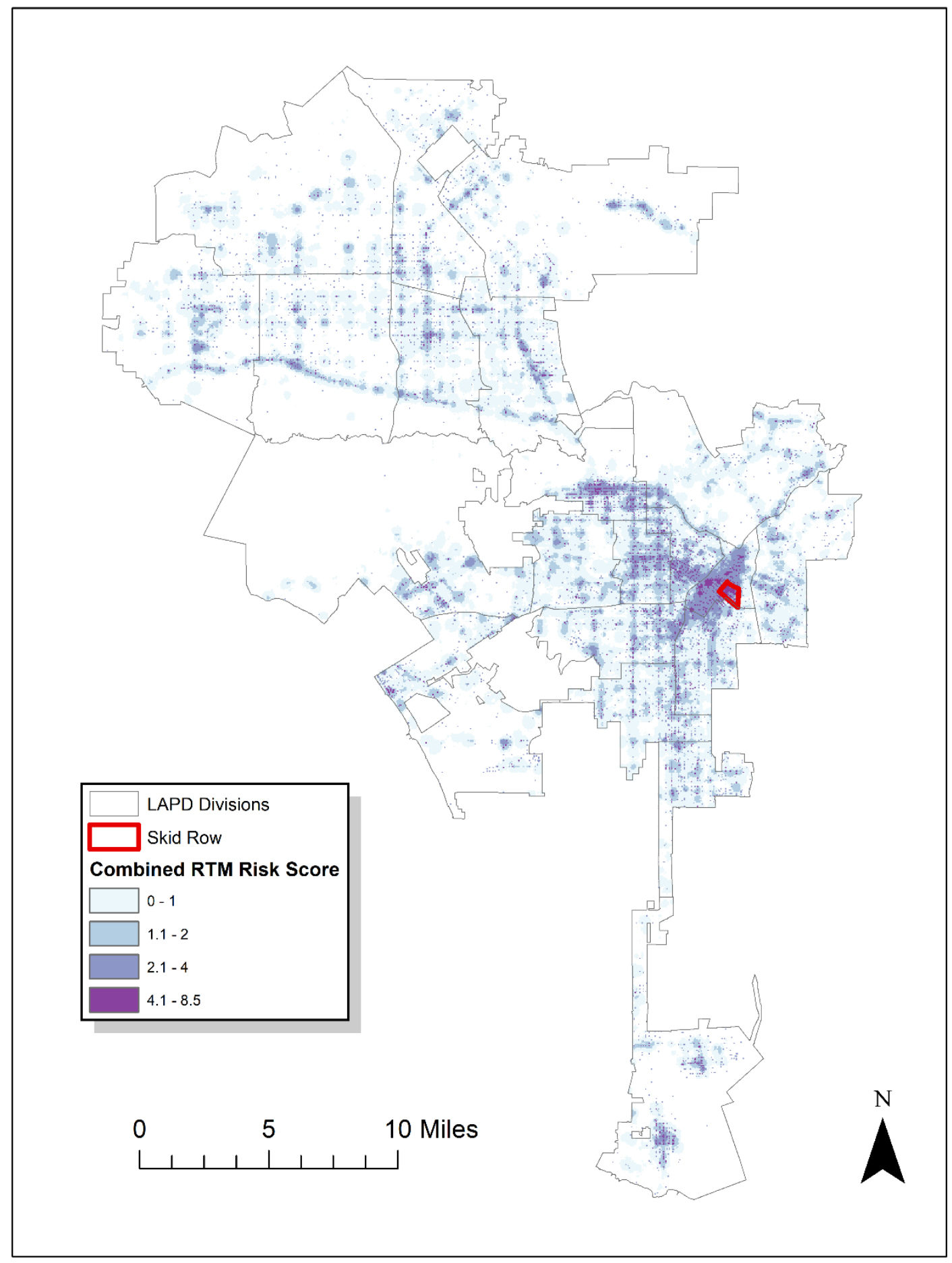

Figure 2: Combined RTM risk score map based on the four different models. 


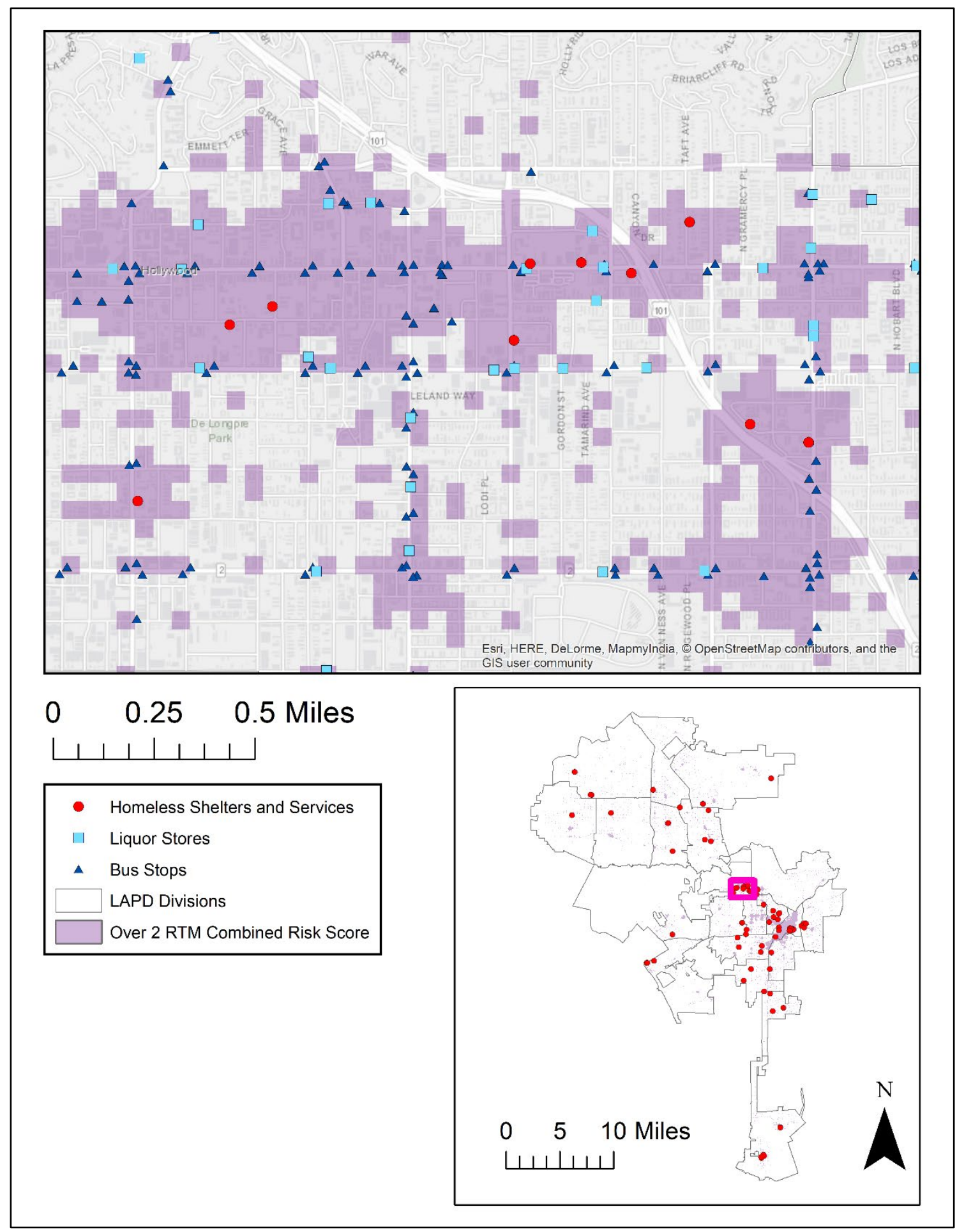

Figure 3: Zoom-in of the high risk area on Hollywood Blvd., illustrating the overlapping risky places of homeless shelters, bus stops, and liquor stores. 
Places can be identified as high risk based on the confluence of multiple factors in nearby proximity, so cannot simply be attributed to one single factor. Figure 3 displays a zoomed in map on the high risk area on Hollywood Blvd. (that is not within skid-row). The background light purple areas display grid cells with a combined RTM risk score of over 2 . This particular area illustrates the high risk associated with multiple homeless shelters and other risk places in close proximity. While bus stops are quite regular throughout the environment, several high risk areas have liquor stores and shelters in close proximity. This zoomed in map does not display all of the different factors that contribute to the elevated risk at the flagged areas, but shows how different high risk areas can be characterized by different overlapping risky places (Connealy \& Piza, 2019; Kennedy et al., 2016; Valasik et al., 2018).

The last analysis we conduct is to determine whether the RTM risk predictions can effectively predict future crime. To do this we use the predictions generated by RTM based on the 2013 through 2017 data, and then evaluate them against homeless related crimes (restricted to the same property and violent crime categories) in 2018. Figure 4 displays the proportion of area under the study on the $\mathrm{X}$ axis, and the $\mathrm{Y}$ axis displays the proportion of 2018 homeless crimes captured based on the combined RTM risk score (Ohyama \& Amemiya, 2018). So the graph can be read as the top 5\% of the RTM risk scores captures approximately $70 \%$ of the homeless related crime in LA.

This graph can be viewed similarly weighted to receiver operator characteristic (ROC) curves, where the weight is the number of crimes, and areas with zero crimes have a weight of one (Mohler \& Porter, 2018). Here the area-under-the-curve statistic is 0.925 , with a $95 \%$ confidence interval of 0.922 to 0.929 . Setting the threshold to identifying high risk areas as above 2 in the combined RTM risk score results in identifying 4\% of the area in LA, and 
captures $68 \%$ of homeless related crimes in 2018 (4,288 out of 6,307$)$ for a predictive accuracy index of over 17. This is excellent evidence that the predictions generated by RTM are effective at forecasting future homeless related crime events.

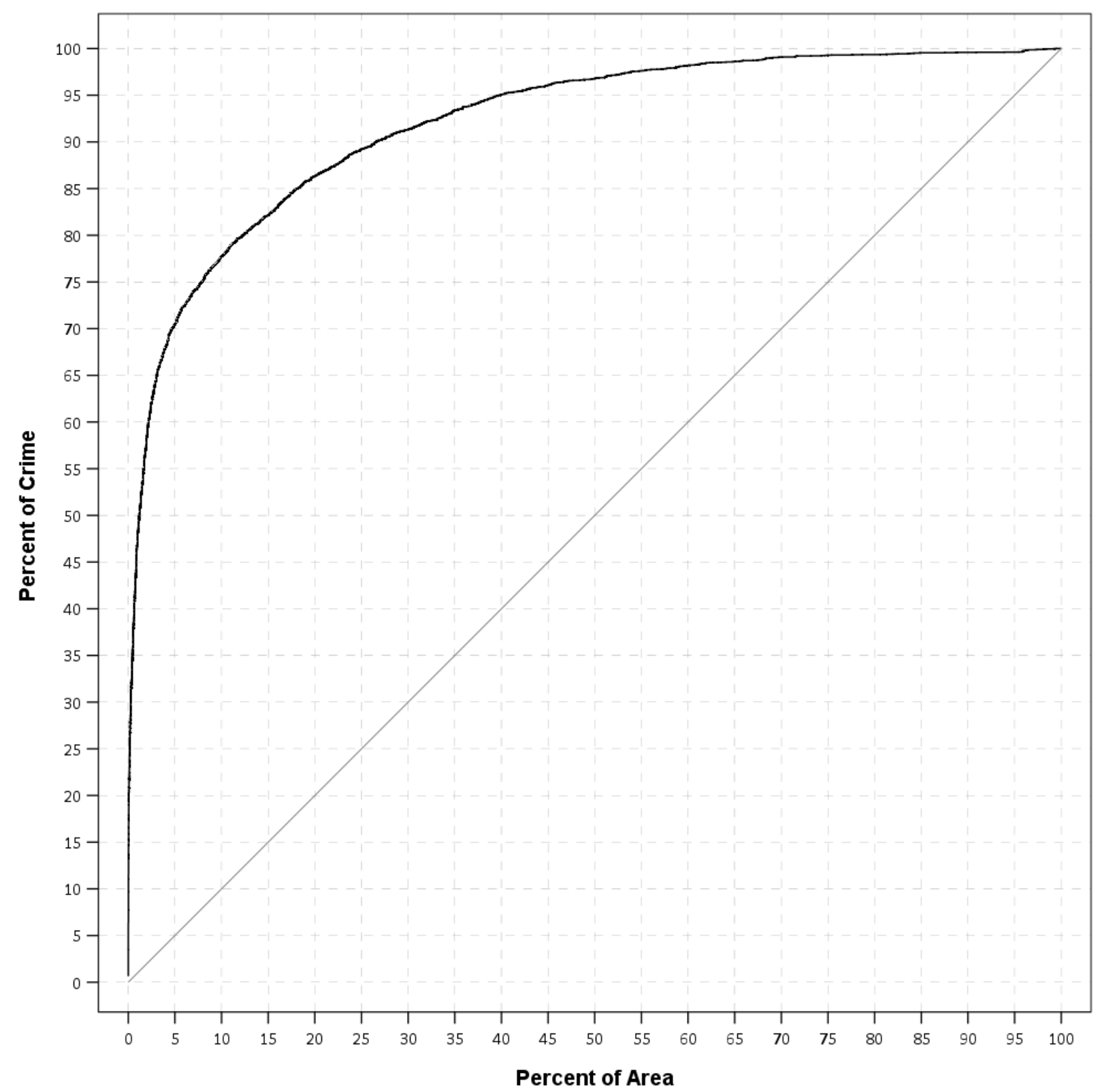

Figure 4: Graph showing the top percent of the area (ranked by the combined RTM risk score based on 2013 to 2017 data) to capture a percent of homeless related crime in 2018. Area-underthe-curve statistic of 0.925 . 


\section{Discussion}

Using RTM we identified several different risk factors that were associated with homeless related crime. The strongest risk factors to predict crime, prior drug arrests and proximity to homeless shelters, are consistent across both property and violent crime types, as well as homeless offending or victimization. Maps of homeless crime risk also illustrated that while homeless related crime is concentrated in the Skid Row neighborhood, there are multiple areas around Los Angeles that both a have a large number of homeless crime incidents, and were predicted to have high homeless crime risk according to the RTM models. We discuss the importance of these findings in terms of advancing the theory of crime at micro places, as well as potential applications of the findings.

Of relevance to theoretical debates in environmental criminology, there is mixed evidence whether one should consider spatial crime patterns as divergent among different types of crime (Andresen \& Linning, 2012; Haberman, 2017), or whether hot spots of crime tend be diverse and overlap in space (Brantingham, 2016). We highlight here another potential way to understand crime problems that do not focus on specific crime types, but that focus on a specific group of individuals. The idea that it may be more appropriate to analyze crimes associated with cognizable groups, as opposed to focusing on specific crime outcomes, is not new. Prior examples are place based analysis of gang violence (Valasik, 2018) or juvenile offending patterns (Bichler, Christie-Merrall, \& Sechrest, 2011; Weisburd, Morris, \& Groff, 2009). Given the findings here that different place based characteristics have very similar effects on homeless related crime, both across property/violent crimes and victim/offender categories, places associated with homeless crime risk may be driving diversity of crime in particular hot spots, at least in Los Angeles. The convergence of individuals who are both potentially motivated 
offenders and suitable targets in a small area can contribute to excess risk among the homeless population, making them a particularly vulnerable group.

This theoretical insight has implications for different strategies intended to mitigate future crime risk committed by or against the homeless. One of the important findings of this work is that risky homeless crime places are both a function of the homeless as offenders as well as homeless victims. While arrest or citation based strategies may potentially deter homeless offenders (Berk \& MacDonald, 2010), they are unlikely to reduce the risk of homeless victimization. At the incident level homeless offending and victimization rarely overlap (homeless offenders victimizing other homeless), and so addressing homeless offenders will not intrinsically reduce homeless victimization risk.

Another prominent risk factor related to homeless crime was that of homeless shelters. While this is not surprising given past work (Faraji et al., 2018), we establish that this risk is due to both more homeless being victimized, as well as more homeless offenders. We also establish that the area of risk is limited to very nearby the homeless shelter, at either a selected distance of 480 or 720 feet for each model. Given that the smallest distance bandwidth of 240 feet was not selected, this suggests that the homeless crime risk is not only limited to within the shelter itself, but has a diffusion effect to the nearby environment. Thus while homeless shelters can likely take particular steps to reduce homeless victimization within their shelter, there may be steps shelters can take to reduce risk outside of the shelter as well. Additionally, we find that the proximity was the selected operationalization for homeless victimization, whereas density was the selected factor for homeless offending. This suggests that to reduce homeless offending one strategy might be to avoid placing homeless shelters nearby to each other, but to spatially diffuse them into larger areas. 
The final consistent risk factor across the different models, Downtown DASH bus stops, had a longer range in which they impacted crime, 1,440 feet. Thus any CPTED intervention that targets risk around bus stops should not be limited to solely the bus stop, but should extend into the environment nearby. This may also provide another opportunity to proactively identify individuals, either as potential offenders or victims. It may also suggest different design based strategies that can reduce the risk of victimization around the bus stops, such as street lighting (Farrington \& Welsh, 2002). It is the case though that such identified risk factors can be due to differing populations using such services (Gerrell, 2018).

When interpreting the results one needs to keep in mind the limitations of the study. The largest is that the analysis is cross-sectional, and subsequently the inferences that these place based factors cause homeless related crime is weak. While it is the case that quasi-experimental designs may provide stronger inferences on particular causal factors (Berk \& MacDonald, 2010; Faraji et al., 2018), these do not necessarily help in identifying more general causal crime factors that contribute to homeless crime risk across all of Los Angeles. The risk factors identified by this RTM analysis can be the first step in the problem identification stage for problem oriented policing approaches to reduce future homeless crime risk (Piza et al., 2018). It is the case that even if certain environmental variables are not the root cause of homeless crime problems, they can still suggest potential intervention strategies.

One way in which such a simplistic cross-sectional analysis may lead one astray is that the stated risk factors may not be entirely exogenous, and themselves may be caused by homeless related crime or have some other spurious association. In particular, this is a strong threat when using prior policing factors, such as drug and prostitution arrests. While these are commonly used as crime attractor measures in previous crime and place research (Bernasco \& 
Block, 2010; Caplan, 2013), it may be the case that police have targeted homeless populations for such offenses, and that explains the association. So increased drug use and prostitution is not a cause of homeless related crime, but a consequence of policing the homeless (Vitale, 2010). This threat is less likely the case though for more fixed aspects of the built environment and commercial establishments, as they tend to be much more temporally stable over time.

A related limitation is that ultimately there could be additional risk factors we have not included in this particular analysis. These omitted variables could potentially be confounds for the place based risk factors that we did identify. For example, vacant homes may be places in which homeless congregate and have increased risk (Spelman, 1993). We were unable to obtain point level estimates of vacant homes in Los Angeles to incorporate into the analysis. Another is the use of 311 calls as a measure of disorder (Caplan et al., 2015; O’Brien \& Winship, 2017; Wheeler, 2018a). This is particularly pertinent, as homeless encampments are often seen as sources of physical disorder (Berk \& MacDonald, 2010). Future work may attempt to identify the overlap of such measures of physical disorder and crime, in an attempt to further identify particular problem solving approaches to homeless related crime.

The last potential confound we have not incorporated in the analysis is demographic factors in predicting homeless related crime risk. It is likely the case that particular demographic factors are not only directly related to homeless crime risk (Dugato, Favarin, \& Bosisio, 2018; Giménez-Santana, Caplan, \& Drawve, 2018; Kim, 2018), but may interact with the place based characteristics that influence crime (Kennedy \& Dugato, 2018; Smith, Frazee, \& Davison, 2000; Thomas \& Drawve, 2018). An obviously meaningful demographic indicator we have not incorporated in the analysis is an actual measure of the local homeless population. Currently counts of homeless populations in LA are generated on a yearly basis and disseminated at the 
larger levels of aggregation, such as census tracts and council areas (see

https://www.lahsa.org/homeless-count/). But these do not aid in providing micro area

predictions. Given the difficulties of accurately measuring the homeless population in small

areas we did not incorporate homeless estimates into the prediction (Kriegler \& Berk, 2010), but there clearly would be utility to doing so in future work.

These additional factors may both improve inferences as to what aspects of the built environment increase homeless related crime risk, as well as potentially improve forecasts of future areas of risk. Here we combine the four different models into one risk surface, and illustrated that it was quite effective and predicting future homeless related crimes. We suspect that incorporating all of the models increased predictive accuracy, as prior work has ensembled different predictions with RTM and illustrated increases in predictive accuracy (Caplan et al., 2019; Drawve et al., 2019). Although future work may further examine whether specific offending or victimization is better predicted in isolation, or whether other models will provide more accurate predictions in space and time.

\section{Conclusion}

Homeless individuals are uniquely exposed to a variety of different risks due to their particular lifestyle. This is both in terms of property crime victimization or violent victimization. In place of traditional policing, it may be interventions designed to reduce homeless victimization risk, as opposed to preventing homeless crime offending, will be more fruitful. Given the history of order maintenance policing strategies in LA, it is likely that using only official reported crimes undercounts the actual prevalence of homeless victimization, as the homeless often intentionally avoid police contact (Stuart, 2016). Even given this limitation 
though it makes the most sense to target those identified spatial areas by RTM for interventions intended to reduce homeless crime risk.

Homeless individuals being victimized provides a potential point where the criminal justice system may intervene with homeless individuals. While informally officers have often served this social work type role, especially when dealing with individuals on Skid Row (Bittner, 1967; Huey, 2007; White, 2010), given that areas of high drug and prostitution arrests are predictive of homeless crime risk, it may be other social service agencies that can aid with homeless related problems should be readily available to officers in those high risk areas.

This strategy relies on reactive policing tactics though; waiting for someone to be victimized and then offering services. Given that proactive hot spot policing strategies tend to be more successful in reducing crime (Braga, Papachristos, \& Hureau, 2012; Braga, Welsh, \& Schnell, 2015), that same idea can likely be extended to tackling homeless crime risk. Instead of focusing on citation based strategies to clear out homeless encampments (Chamard, 2010; Vitale, 2010; Stuart, 2016; Wilking et al., 2018), officers may attempt to reduce victimization risk in these areas. Something as simple as providing the homeless with better services to store valuables is likely a way to reduce property crime risk. Officers may proactively seek out individuals who are at higher risk due to their particular belongings and then suggest such services.

Additionally, the results of RTM can also be used by other non-police agencies to identify priority targeted areas. The findings should be of interest to homeless shelters themselves, as they will likely want to take steps to not only mitigate risk inside of the shelter, but to nearby areas as well. Identified areas of high victimization risk are also areas that should be prioritized to attempt to either provide services to shelter current individuals, or at least 
provide other means through which the risk of this vulnerable population is mitigated to whatever extent possible.

The current work can only be considered the start of identifying potential risk factors for homeless crime risk, not the end. While such analysis can be helpful in identifying strategies, ultimately those strategies need to be evaluated for their efficacy. We suspect going forward that spatial policing strategies intended to address homeless related crime will need to go beyond order maintenance based strategies given the limited utility of those prior strategies (Berk \& MacDonald, 2010; Braga et al., 2015). Given that homeless related crime involves both risk to homeless individuals, as well as risk of homeless individuals committing crime, effective crime reduction strategies likely need to consider both of these elements to effectively reduce homeless related crime. While RTM often explicitly discusses focusing on places instead of people, it is likely the case that to truly understand homeless related crime and its antecedents one needs to understand both.

\section{References}

Andresen, M.A. (2006) Crime measures and the spatial analysis of criminal activity. British Journal of Criminology 46, 258-285.

Andresen, M.A., \& Linning, S.J. (2012) The (in)appropriateness of aggregating across crime types. Applied Geography 35, 275-282.

Barnum, J.D., Caplan, J.M., Kennedy, L.W., \& Piza, E.L. (2017) The crime kaleidoscope: A cross-jurisdictional analysis of place features and crime in three urban environments. Applied Geography 79, 203-211.

Berk, R., \& MacDonald, J. (2010) Policing the homeless: An evaluation of efforts to reduce homeless-related crime. Criminology \& Public Policy 9(4): 813-840.

Bernasco, W., \& Block, R.L. (2010) Robberies in Chicago: A block-level analysis of the influence of crime generators, crime attractors, and offender anchor points. Journal of Research in Crime \& Delinquency 48, 33-57.

Bichler, G., Christie-Merrall, J., Sechrest, D. (2011) Examining juvenile delinquency within activity space: Building a context for offender travel patterns. Journal of Research in Crime \& Delinquency 48(3): 472-506. 
Bittner, E. (1967) The police on skid row: A study of peace keeping. American Sociological Review 32, 699-715.

Block, R.L., \& Block, C.R. (1995) Space, place, and crime: Hot spot areas and hot places of liquor-related crime. Crime Prevention Studies 4, 145-184.

Boggs, S.L. (1965) Urban crime patterns. American Sociological Review 30, 899-908.

Bowers, K. (2014) Risky facilities: Crime radiators or crime absorbers? A comparison of internal and external levels of theft. Journal of Quantitative Criminology 30, 389-414.

Braga, A.A., Papachristos, A.V., \& Hureau, D.M. (2012) The effects of hot spots policing on crime: An updated systematic review and meta-analysis. Justice Quarterly 31, 633-663.

Braga, A.A., Welsh, B.C., \& Schnell, C. (2015) Can policing disorder reduce crime? A systematic review and meta-analysis. Journal of Research in Crime \& Delinquency 52, 567-588.

Brantingham, P.L., \& Brantingham, P.J. (1993) Nodes, paths and edges: Considerations on the complexity of crime and the physical environment. Journal of Environmental Pyschology $13,3-28$.

Brantingham, P.L., \& Brantingham, P.J. (1995) Criminality of place. European Journal on Criminal Policy and Research 3, 5-26.

Brantingham, P.J. (2016) Crime diversity. Criminology 54, 553-586.

Burgason, K.A., Drawve, G., Brown, T.C., \& Eassey, J. (2017) Close only counts in alcohol and violence: Controlling violence near late-night alcohol establishments using a routine activities approach. Journal of Criminal Justice 50, 62-68.

Caplan, J.M. (2011) Mapping the spatial influence of crime correlates: A comparison of operationalization schemes and implications for crime analysis and criminal justice practice. Cityscape 13, 57-83.

Caplan, J.M., \& Kennedy, L.W. (2016) Risk Terrain Modeling: Crime Prediction and Risk Reduction. University of California Press: Berkeley, CA.

Caplan, J.M., Kennedy, L.W., \& Miller, J. (2011) Risk terrain modeling: Brokering criminological theory and GIS methods for crime forecasting. Justice Quarterly, 28(2): 360-381.

Caplan, J.M., Kennedy, L.W., Barnum, J.D., \& Piza, E.L. (2015) Risk terrain modeling for spatial risk assessment. Cityscape 17, 7-16.

Caplan, J.M., Kennedy, L.W., Barnum, J.D., \& Piza, E.L. (2017) Crime in context: Utilizing risk terrain modeling and conjunctive analysis of case configurations to explore the dynamics of criminogenic behavior settings. Journal of Contemporary Criminal Justice 33, 133151. 
Caplan, J.M., Kennedy, L.W., Piza, E.L., \& Barnum, J.D. (2019) Using vulnerability and exposure to improve robbery prediction and target area selection. Applied Spatial Analysis and Policy Online First

Chamard, S. (2010) Homeless Encampments. Problem Oriented Policing Guide Number 56. https://popcenter.asu.edu/content/homeless-encampments-print-full-guide.

Cohen, L.E., \& Felson, M. (1979) Social change and crime rate trends: A routine activity approach. American Sociological Review 44, 588-608.

Connealy, N.T., \& Piza, E.L. (2019) Risk factor and high-risk place variations across different robbery targets in Denver, Colorado. Journal of Criminal Justice 60, 47-56.

Crawford, D.M., Whitbeck, L.B., \& Hoyt, D.R. (2011) Propensity for violence among homeless and runaway adolescants: An event history analysis. Crime \& Delinquency 57, 950-968.

Diette, T.M., \& Ribar, D.C. (2018). A longitudinal analysis of violence and housing insecurity. Economic Inquiry 56, 1602-1621.

Drawve, G. (2016). A metric comparison of predictive hot spot techniques and RTM. Justice Quarterly, 33, 369-397.

Drawve, G., Grubb, J., Steinman, H., \& Belongie, M. (2019). Enhancing data-driver law enforcement efforts: Exploring how Risk Terrain Modeling and conjunctive analysis fit in a crime and traffice safety framework. American Journal of Criminal Justice 44, 106124.

Dugato, M., Favarin, S., \& Bosisio, A. (2018) Isolating target and neighborhood vulnerabilities in crime forecasting. European Journal of Criminal Policy and Research 24, 393-415.

Ellsworth, J.T. (2018) Street crime victimization among homeless adults: A review of the literature. Victims \& Offenders: An International Journal of Evidence-based Research, Policy, and Practice Online First.

Eck, J.E. (2018) Regulation for high-crime places: Theory, evidence, and principles. The ANNALS of the American Academy of Political and Social Science 679(1): 106-120.

Faraji, S.L., Ridgeway, G., \& Wu, Y. (2018) Effect of emergency winter homeless shelters on property crime. Journal of Experimental Criminology 14(2): 129-140.

Farrington, D.P., \& Welsh, B.C. (2002) Improved street lighting and crime prevention. Justice Quarterly 19, 313-342.

Fischel, W. (2015) Zoning rules! The economics of land use regulation. Cambridge, MA: Lincoln Institute of Land Policy.

Gerell, M. (2018) Bus stops and violence, are risky places really risky? European Journal on Criminal Policy and Research 24, 351-371. 
Giménez-Santana, A., Caplan, J.M., \& Drawve, G. (2018) Risk terrain modeling and socioeconomic stratification: Identifying risky places for violent crime victimization in Bogotá, Colombia. European Journal on Criminal Policy and Research 24, 417-431.

Groff, E.R., \& La Vigne, N.G. (2001) Mapping an opportunity surface of residential burglary. Journal of Research in Crime \& Delinquency 38, 257-278.

Haberman, C.P. (2017) Overlapping hot spots? Examination of the spatial heterogeneity of hot spots of different crime types. Criminology \& Public Policy 16, 633-660.

Haberman, C.P., \& Ratcliffe, J.H. (2015) Testing for temporally differentiated relationships among potentially criminogenic places and census block street robbery counts. Criminology 53, 457-483.

Haberman, C.P., Sorg, E.T., \& Ratcliffe, J.H. (2018) The seasons they are a changin': Testing for seasonal effects of potentially criminogenic places on street robbery. Journal of Research in Crime \& Delinquency 55, 425-459.

Hipp, J.R. (2019) General theory of spatial crime patterns. Criminology 54, 653-679.

Hipp, J.R., \& Kim, Y. (2019) Explaining the temporal and spatial dimensions of robbery: Differences across measures of the physical and social environment. Journal of Criminal Justice 60, 1-12.

Hipp, J.R., Tita, G.E., \& Boggess, L.N. (2011) A new twist on an old approach: A randominteraction approach for estimate rates of inter-group interaction. Journal of Quantitative Criminology 27, 27-51.

Huey, L. (2007) Negotiating demands: The politics of skid row policing in Edinburgh, San Francisco, and Vancouver. University of Toronto Press.

Jeanis, M.N., Fox, B.H., Muniz, C.N. (2018) Revitalizing profiles of runaways: A latent class analysis of delinquenty runaway youth. Child and Adolescent Social Work Journal, Online First.

Kennedy, L.W., Caplan, J.M., \& Piza, E. (2010) Risk clusters, hotspots, and spatial intelligence: Risk terrain modeling as an algorithm for police resource allocation. Journal of Quantitative Criminology 27, 339-362.

Kennedy, L.W., Caplan, J.M., Piza, E., \& Buccine-Schraeder, H. (2016) Vulnerability and exposure to crime: Applying risk terrain modeling to the study of assault in Chicago. Applied Spatial Analysis and Policy 9, 529-548.

Kennedy, L.W., \& Dugato, M. (2018) Forecasting crime and understanding its causes. Applying risk terrain modeling worldwide. European Journal on Criminal Policy and Research 24, 345-350. 
Kim, Y. (2018) Examining the relationship between the structural characteristics of place and crime by imputing census block data in street segments: Is the pain worth the gain? Journal of Quantitative Criminology 34, 67-110.

Kubrin, C.E., \& Hipp, J.R. (2016) Do fringe banks create fringe neighborhoods? Examining the spatial relationship between fringe banking and neighborhood crime rates. Justice Quarterly 33, 755-784.

Kriegler, B., \& Berk, R. (2010) Small area estimation of the homeless in Los Angeles: An application of cost-sensitive stochastic gradient boosting. The Annals of Applied Statistics 4, 1234-1255.

Lee, B.A., \& Schreck, C.J. (2005) Danger on the streets: Marginality and victimization among homeless people. American Behavioral Scientist 48, 1055-1081.

Lemieux, A., \& Felson, M. (2012) Risk of violent crime victimization during major daily activities. Violence and Victims 27, 635-655.

Lersch, K.M. (2017) Risky places: An analysis of carjackings in Detroit. Journal of Criminal Justice 52, 34-40.

Linning, S.J. (2015) Crime seasonality and the micro-spatial patterns of property crime in Vancouver, BC and Ottawa, ON. Journal of Criminal Justice 43, 544-555.

Listwan, S.J., Hartman, J.L., \& LaCourse, A. (2018) Impact of the MeckFUSE Pilot Project: Recidivism among the chronically homeless. Justice Evaluation Journal 1(1): 96-108.

Malleson, N., \& Andresen, M.A. (2015) The impact of using social media data in crime rate calculations: Shifting hot spots and changing spatial patterns. Cartography and Geographic Information Science 42, 112-121.

McCord, E.S., Ratcliffe, J.H., Garcia, R.M., \& Taylor, R.B. (2007) Nonresidential crime attractors and generators elevate perceived neighborhood crime and incivilities. Journal of Research in Crime \& Delinquency 44, 295-320.

Mohler, G.O., \& Porter, M.D. (2018) Rotational grid, PAI-maximizing crime forecasts. Statistical Analysis and Data Mining 11, 227-236.

Newman, O. (1973) Defensible space: Crime prevention through urban design. MacMillan: New York, NY.

O’Brien, D.T., \& Winship, C. (2017) The gains of greater granularity: The presences and persistence of problem properties in urban neighborhoods. Journal of Quantitative Criminology 33, 649-674.

Ohyama, T, \& Amemiya, M. (2018) Applying crime prediction techniques to Japan: A comparison between risk terrain modeling and other methods. European Journal on Criminal Policy and Research 24: 469-487. 
Perenzin Askey, A., Taylor, R., Groff, E., \& Fingerhut, A. (2018) Fast food restaurants and convenience stores: Using sales volume to explain crime patterns in Seattle. Crime \& Delinquency 64, 1836-1857.

Piza, E.L., Kennedy, L.W., \& Caplan, J.M. (2018) Facilitators and impediments to designing, implementing, and evaluating risk-based policing strategies using risk terrain modeling: Insights from a multi-city evaluation in the United States. European Journal of Criminal Policy and Research 24, 489-513.

Robinson, T. (2017) No right to rest: Police enforcement patterns and quality of life consequences of the criminalization of homelessness. Urban Affairs Review Online First.

Scott, M.S. (2003). Panhandling. Problem-Oriented Guides for Police, No. 13. U.S. Department of Justice. Office of Community Oriented Policing Services.

Smith, W.R., Frazee, S.G., \& Davison, E.L. (2000) Furthering the integration of routine activity and social disorganization theories: Small units of analysis and the study of street robbery as a diffusion process. Criminology 38, 489-524.

Spelman, W. (1993) Abandoned buildings: Magnets for crime? Journal of Criminal Justice 21, 481-495.

Stuart, F. (2016) Becoming "Copwise": Policing, culture, and the collateral consequences of street-level criminalization. Law \& Society Review 50, 279-313.

Taylor, R.B. (2015) Community criminology: Fundamentals of spatial and temporal scaling, ecological indicators, and selectivity bias. NYU Press: New York, NY.

Thomas, S.A., \& Drawve, G. (2018) Examining interactive effects of characteristics of the social and physical environment on aggravated assault. Journal of Criminal Justice 57, 89-98.

U.S. News (2017) America's homeless population rises for first time in years. Retrieved from https://www.usnews.com/news/us/articles/2017-12-06/us-homeless-count-rises-pushedby-crisis-on-the-west-coast.

Valasik, M. (2018) Gang violence predictability: Using risk terrain modeling to study gang homicides and gang assaults in East Los Angeles. Journal of Criminal Justice 58, 10-21.

Valasik, M., Brault, E., \& Martinez, S.M. (2018) Forecasting homicide in the red stick: Risk terrain modeling and the spatial influence of urban blight on lethal violence in Baton Rouge, Louisiana. Social Science Research, Online First.

Vitale, A.S. (2010) The Safer Cities Initiative and the removal of the homeless: Reducing crime or promoting gentrification on Los Angeles' Skid Row? Criminology \& Public Policy, 9(4): 867-873.

Weisburd, D., Morris, N.A., \& Groff, E.R. (2009) Hot spots of juvenile crime: A longitudinal study of arrest incidents at street segments in Seattle, Washington. Journal of Quantitative Criminology 25, 443-467. 
Wheeler, A.P. (2018a) The effect of 311 calls for service on crime in D.C. at microplaces. Crime \& Delinquency 64, 1882-1903.

Wheeler, A.P. (2018b) Quantifying the local and spatial effects of alcohol outlets on crime. Crime \& Delinquency, Online First.

Wilson, J.Q., \& Kelling, G.L. (1982) The police and neighborhood safety: Broken windows. The Atlantic 127, 29-38.

White, M.D. (2010) Jim Longstreet, Mike Marshall, and the lost art of policing skid row. Criminology \& Public Policy 9(4): 883-896.

Wilking, J., Roll, S., Philhour, D. Hansen, P., \& Nevarez, H. (2018) Understanding the implications of a punitive approach to homelessness: A local case study. Poverty \& Public Policy 10(2): 159-176. 